\title{
Marathon performance but not BMI affects post-marathon pro-inflammatory and cartilage biomarkers
}

\author{
Annegret Mündermann, Ph.D. ${ }^{\text {a }}$ \\ Jeroen Geurts, Ph.D. ${ }^{\mathrm{a}}$ \\ Thomas Hügle, M.D./Ph.D. ${ }^{\text {a }}$ \\ Thomas Nickel, M.D./Ph.D. ${ }^{b}$ \\ Arno Schmidt-Trucksäss, M.D. ${ }^{\mathrm{c}}$ \\ ${ }^{1}$ Martin Halle, M.D. ${ }^{\text {de,f }}$ \\ ${ }^{1}$ Henner Hanssen, M.D. ${ }^{\text {c,d }}$
}

${ }^{\mathrm{a} C}$ Clinic for Orthopaedics and Traumatology, University Hospital Basel, Switzerland

${ }^{\mathrm{b}}$ Medizinische Klinik und Poliklinik 1, Campus Grosshadern, Ludwig-MaximiliansUniversität München, Munich, Germany

${ }^{c}$ Department of Sport, Exercise and Health, University of Basel, Switzerland

${ }^{\mathrm{d}}$ Department of Prevention and Sports Medicine, Technische Universität München, Germany

${ }^{\mathrm{e}}$ Deutsches Zentrum für Herz-Kreislauf-Forschung (DZHK), partner site Munich Heart Alliance, Munich, Germany

${ }^{\mathrm{f}}$ Else Kröner-Fresenius-Zentrum, Klinikum rechts der Isar, Technische Universität München, Munich, Germany

Original Investigation

This is an Accepted Manuscript of an article published by Taylor \& Francis in Journal of Sports Sciences on May 11 2016, available online http://dx.doi.org/10.1080/02640414.2016.1184301.

Address for correspondence: PD Dr. Annegret Mündermann

Clinic for Orthopaedics and Traumatology

University Hospital Basel

Spitalstrasse 21

4031 Basel, Switzerland

Tel. +41612659444

Email annegret.muendermann@unibas.ch

Word count: 3,221 words

Running title: Marathon performance, BMI and biomarkers

Key words: cartilage biomarkers, tissue metabolism, marathon running, proinflammatory markers, obesity

Acknowledgements: The authors thank Immunodiagnostic Systems for providing the COMP ELISA kits. The sponsor did not have a role in any aspect of this study.

${ }^{1}$ Martin Halle and Henner Hanssen share senior authorship. 


\begin{abstract}
We tested the hypothesis that changes in serum cartilage oligomeric matrix protein (COMP), tumor-necrosis factor $\alpha$ (TNF- $\alpha$ ), interleukin-6 (IL-6) and high-sensitivity Creactive protein (hsCRP) concentration after regular endurance training and running a marathon race depend on body mass index (BMI) and/or on marathon performance. Blood samples were collected from 45 runners of varying BMI and running experience before and after a 10-week marathon training program and before, immediately and 24 hours after a marathon race. Serum biomarker concentrations, BMI and marathon finishing time were measured. The mean $(95 \%$ confidence interval $(\mathrm{CI}))$ changes from before to immediately after the marathon were: COMP: 4.09U/L (3.39-4.79U/L); TNF$\alpha:-1.17 \mathrm{mg} / \mathrm{L}(-2.58-0.25 \mathrm{mg} / \mathrm{L})$; IL-6: $12.0 \mathrm{pg} / \mathrm{mL}(11.4-12.5 \mathrm{pg} / \mathrm{mL})$; and hsCRP: $0.08 \mathrm{pg} / \mathrm{mL}(-0.14-0.3 \mathrm{pg} / \mathrm{mL})$. The mean $(95 \% \mathrm{CI})$ changes from immediately after to 24 hours after the marathon were: COMP: $0.35 \mathrm{U} / \mathrm{L}(-0.88-1.57 \mathrm{U} / \mathrm{L})$; TNF- $\alpha$ : $-0.43 \mathrm{mg} / \mathrm{L}$ (-0.99-0.13mg/L); IL-6: -9.9pg/mL (-10.5--9.4pg/mL); and hsCRP: $1.52 \mathrm{pg} / \mathrm{mL}(1.25-$ $1.79 \mathrm{pg} / \mathrm{mL}$ ). BMI did not affect changes in biomarker concentrations. Differences in marathon finishing time explained $32 \%$ of variability in changes in serum hsCRP and $28 \%$ of variability in changes in serum COMP during the 24-hour recovery after the marathon race $(P<0.001)$. Slower marathon finishing time but not a higher BMI modulates increases in pro-inflammatory markers or cartilage markers following a marathon race.
\end{abstract}




\section{INTRODUCTION}

In recent years, marathon running has become increasingly popular with more than 700 races worldwide and up to 50’000 participants per event (Schiffer, Montiel, Hildebrandt, Predel, \& Knackstedt, 2010). These events attract participants with diverse athletic backgrounds from elite runners to novices and different body compositions ranging from lean to obese participants (Vadeboncoeur et al., 2012). However, until recently, the health implications of larger body mass index (BMI) in long distance running have received little attention.

Being obese (defined as BMI $\left.>30 \mathrm{~kg} / \mathrm{m}^{2}\right)$ or overweight $\left(25<\mathrm{BMI} \leq 30 \mathrm{~kg} / \mathrm{m}^{2}\right)$ represents a greater demand for the cardiovascular system and has been associated with a greater risk for cardiovascular disease (Despres, 2012) and subclinical inflammation (Hsieh, Wang, \& Chen, 2014), which can lead to insulin resistance and metabolic syndrome (Bastard et al., 2006). Elevated plasma concentrations of pro-inflammatory cytokines (including tumor-necrosis-factor alpha (TNF- $\alpha$ ) and interleukin-6 (IL-6)) and high-sensitivity C-reactive protein (hsCRP) are typical for obese persons (Kasapis \& Thompson, 2005). Aerobic exercise in active obese persons modulates the immune system response, increases inflammatory resistance, and mediates cardiovascular protection (Nickel et al., 2011) with an immediate increase in IL-6 and IL-10 levels and a delayed increase in TNF- $\alpha$ and CRP-levels after a marathon run (Nickel, Emslander, et al., 2012). Hence, regular exercise training as well as acute bouts of exercise affect inflammatory markers. Moreover, inflammation plays a role in the pathomechanics of osteoarthritis (OA) in obese persons (Andriacchi et al., 2004).

Serum concentrations of cartilage biomarkers are frequently used as surrogates for cartilage turnover, and these concentrations respond to physiological load. For instance, serum concentrations of cartilage oligomeric matrix protein (COMP) increase 
after exercise bouts of walking (Mündermann, Dyrby, Andriacchi, \& King, 2005; Mündermann, King, Smith, \& Andriacchi, 2009; Pruksakorn et al., 2013), running (Kersting, Stubendorff, Schmidt, \& Bruggemann, 2005; Niehoff et al., 2010; Niehoff et al., 2011) and marathon running (Neidhart et al., 2000) but not after deep knee bends (Niehoff et al., 2010). Hence, load-induced changes in COMP appear to be sensitive to load magnitude. Serum COMP has been associated with the incidence of knee OA (Saberi Hosnijeh, Runhaar, van Meurs, \& Bierma-Zeinstra, 2015), and load-induced changes in serum COMP predict changes in cartilage thickness in patients with knee OA (Erhart-Hledik et al., 2012). However, the prevalence of knee osteoarthritis in former elite marathon runners is not higher than that in the general population (Schmitt, Rohs, Schneider, \& Clarius, 2006). In contrast, greater joint loads have been identified as factor involved in the greater prevalence of knee OA in obese persons (Vincent, Heywood, Connelly, \& Hurley, 2012), and obese persons ambulate with altered joint mechanics compared to normal-weight persons (Messier et al., 2014; Runhaar, Koes, Clockaerts, \& Bierma-Zeinstra, 2011). These ambulatory differences may contribute to an earlier initiation of osteoarthritic changes in obese persons (Andriacchi \& Mündermann, 2006). To date the effect of regular endurance training compared to acute marathon running on cartilage biomarkers in overweight or obese athletes has not been investigated.

Weight loss in combination with increased physical activity, a negative energy balance, and diet adjustment has been associated with lower inflammation and consequently with lower cardiovascular risk factors in obese persons (Petelin et al., 2014) and resulted in lower serum COMP (Bartels et al., 2014). Moreover, exercise training programs lead to reductions in serum COMP in healthy persons (Celik, Salci, Ak, Kalaci, \& Korkusuz, 2013). However, a potential modulating effect of 
inflammation on load-induced changes in serum COMP in normal-weight and obese experienced and novice runners has not been investigated.

The purpose of this study was to test if changes in serum COMP, TNF- $\alpha$, IL-6 and hsCRP concentration in response to regular endurance training and running a marathon race depend on BMI and/or on marathon performance.

\section{METHODS}

\section{Participants}

Forty-five male runners were included in this observational substudy of a previously published intervention study (Nickel, Emslander, et al., 2012; Nickel et al., 2011; Nickel, Vogeser, et al., 2012) (clinicaltrials.gov identifier: NCT00500773). Briefly, participants were recruited from a group of runners with varying BMI and previous running experience (Table 1) undergoing 10-week running training before completing a marathon race. All participants provided informed written consent prior to participation. The original study was conducted in 2007 in Munich (Germany). The study was approved by the institutional ethics committee and conducted in accordance with the Declaration of Helsinki. Only healthy male runners aged 30-60 years without any cardiovascular risk factor other than weight were included. Other exclusion criteria were known coronary or structural heart disease, insulin-dependent diabetes mellitus, drug treatment for type 2 diabetes or hypertension, hyperlipoproteinemia, renal dysfunction, chronic inflammation, and musculoskeletal disorder.

\section{Study protocol}

Anthropometric measurements including body fat composition (caliper measurement) and fasting (overnight) blood samples were taken 2 to 5 days before and 
after a 10-week running endurance training program (Figure 1). The training program was scheduled for the 10 -weeks immediately preceding the marathon race so that the blood sample at the end of the training period was taken 2 days before the marathon. Participants fasted before blood sampling and avoided acute bouts of exercise 2 days prior to the examination. Additional blood samples were taken immediately after and 24 hours after the marathon race.

\section{Endurance training protocol}

The 10-week running endurance training comprised continuous aerobic and interval training including warm-up and cool-down periods with a gradual increase in duration and intensity during the course of the 10-week training program. An individual training program for each participant was prescribed with regard to current fitness levels. The intensity of the training was given by individual target heart rates monitored by heart rate monitors. Supervised exercise training was offered four times per week under medical supervision. Training was documented with respect to intensity, duration, and kilometres run per week by a written protocol.

\section{IL-6, TNF- $\alpha$, hsCRP and COMP}

Blood was collected and allowed to clot for $30 \mathrm{~min}$. Sera were separated and frozen to $-20^{\circ} \mathrm{C}$ within 1 hour of collection and then transferred for storage at $-80^{\circ} \mathrm{C}$ until assayed. Samples were defrosted and IL-6, TNF- $\alpha$, hsCRP and COMP levels were examined using cytokine- and protein-specific ELISA kits according to the manufacturers' instructions (IL-6: Bender Med-Systems, Austria; TNF- $\alpha$ : Biosource, USA; hsCRP: Biosource, USA; COMP: Anamar, Sweden). All samples of each participant were tested on the same plate to preclude the effect of inter-assay variability. 
All samples were tested in duplicates, and the intra-assay and inter-assay coefficients of variation were $\leq 5 \%$.

\section{Statistical analysis}

All statistical analyses were performed in SPSS version 22.0 (IBM Corporation, Armonk, NY). Normal distribution of data were confirmed using Kolmogorov Smirnov tests. Changes in demographics between time points were detected using analysis of variance for repeated measures $(P<0.05)$ with Student t-test for dependent measures as posthoc tests with Bonferroni correction $(P<0.01)$. Linear mixed models were used to detect significant changes in serum biomarker concentrations over time with covariates BMI and marathon finishing time $(P<0.05)$. Posthoc comparisons were performed using Student t-test for dependent measures with Bonferroni correction $(P<0.006)$. Stepwise linear regression models were used to detect the effects of BMI and marathon finishing times on changes in serum biomarkers from before to after and from immediately after to 24 hours after the marathon race $(P<0.05)$. Participants were grouped into tertile groups based on their marathon finishing time. Differences in changes in biomarkers between tertile groups were detected using linear mixed models with tertile group as between-subject factor and time as within-subject factor $(P<0.05)$.

\section{RESULTS}

On average, participants ran between 12 and $78 \mathrm{~km}$ per week during the 10week endurance running training (Table 1). While only small but significant reductions in body mass, BMI and waist circumference were observed $(-1.6 \%,-2.0 \%$ and $-2.1 \%$; $P<0.001$ ), body fat was $11.0 \%$ lower after the 10 -week endurance training period compared to baseline $(P<0.001$; Table 1$)$. BMI ranged from 17.0 to $36.5 \mathrm{~kg} / \mathrm{m}^{2}$. Overall, 
1, 24, 16 and 4 participants were classified as underweight $\left(\mathrm{BMI} \leq 20 \mathrm{~kg} / \mathrm{m}^{2}\right)$, normal $\left(20<\mathrm{BMI} \leq 25 \mathrm{~kg} / \mathrm{m}^{2}\right)$, overweight $\left(25<\mathrm{BMI} \leq 30 \mathrm{~kg} / \mathrm{m}^{2}\right)$ and obese $(\mathrm{BMI}>30$ $\mathrm{kg} / \mathrm{m}^{2}$ ), respectively. Marathon finishing time ranged from 2:56 to 5:32 hours (Table 1). Differences in serum concentrations between time points were observed for IL-6, hsCRP and COMP $(P<0.005)$ but not for TNF- $\alpha(P=0.88$; results of generalized linear models; Table 2). Serum IL-6 showed an elevenfold increase during the marathon race and decreased to 2.8 times the baseline level within 24 hours after the marathon race (Figure 2). Serum hsCRP showed small but significant changes during the training and marathon race and a more than hundredfold increase in the 24 hours after the marathon race (Figure 3). Serum COMP increased by 39\% during the marathon race and remained elevated 24 hours after the marathon race. The variability in all serum concentrations was greater 24 hours after the marathon than at all other time points (except for TNF- $\alpha$ at baseline; Figures 2 and 3).

BMI did not affect changes in serum in IL-6, TNF- $\alpha$, hsCRP and COMP $(P>0.75)$. Differences in marathon finishing time explained $32 \%$ of variability in changes in serum hsCRP and $28 \%$ of variability in changes in serum COMP during the 24-hour recovery after the marathon race $(P<0.001$; Table 3$)$. Runners were grouped into tertile groups by marathon finishing time (Table 1). The slowest third based on marathon finishing time had the greatest increase in hsCRP and a further increase in COMP 24 hours after the marathon race while the fastest third had the smallest increase in hsCRP and the largest decrease in COMP 24 hours after the marathon race (Figure 4). Changes in IL-6 and TNF- $\alpha$ did not correlate with marathon finishing time $\left(\mathrm{R}^{2}<.04\right)$. While the required sample size was not calculated a priori because this study was a subanalysis of a study on cardiovascular factors, posthoc analyses revealed that all statistically significant results in this study had a power above $80 \%$ 


\section{DISCUSSION}

The purpose of this study was to determine the interrelation between changes in serum COMP, TNF- $\alpha$, IL- 6 and hsCRP concentration in response to regular endurance training and running a marathon race depending on BMI and/or on marathon performance. Serum COMP and IL-6 increased immediately after while hsCRP and although not significantly - TNF- $\alpha$ concentrations increased 24 hours after running a marathon. BMI was not related to these changes during training and immediately and 24 hours after the marathon race. In contrast, changes in hsCRP and COMP within 24 hours after the marathon race depended on marathon finishing time. These results provide first evidence that the inflammatory and cartilage responses to marathon running do not depend on BMI but on marathon performance.

\section{BMI and biomarkers}

Contrary to our hypothesis, BMI did not affect the response of the biomarkers tested in this study. Moreover, including body fat, waist circumference and hip circumference in our linear regression model (results not reported) did not affect the results. Several benefits of running on general health have been reported. For instance, running programs result in weight loss and decrease in diastolic blood pressure in obese persons (Schjerve et al., 2008), and exercise-induced improvement in microvascular function in obese runners has been previously demonstrated (Hanssen et al., 2011). Moreover, running more than $63 \mathrm{~km}$ per week on average substantially diminishes the risk for inherited obesity (Williams, 2012). 


\section{Marathon finishing time and biomarkers}

Pro-inflammatory biomarkers

IL-6 is a pro-inflammatory cytokine secreted by T-cells and macrophages and is released by skeletal muscles in response to endurance exercise. In this study, serum concentrations of IL-6 were elevated immediately after the marathon race and returned to close to baseline levels within 24 hours after the marathon in all runners indicating a recovery of muscle metabolism within 24 hours after the marathon race independent of marathon finishing time. This result is in agreement with the literature (Neidhart et al., 1997). TNF- $\alpha$ is a cytokine and mediator of systemic inflammation and involved in acute phase reactions. In contrast to IL-6, TNF- $\alpha$ levels increased within 24 hours after the marathon race in most runners. Neidhardt et al. (Neidhart et al., 1997) reported an increase in TNF- $\alpha$ during a marathon race that remained elevated up to 24 hours after the race. These results suggest an inflammatory response that is independent of muscle load experienced during the marathon race. Interestingly and contrary to previous reports (Kasapis \& Thompson, 2005), IL-6 and TNF- $\alpha$ levels were not related to BMI in our study. In this study, we only included runners without any cardiovascular risk factor other than weight and without clinical inflammation. Hence, BMI does not have a modulating effect on serum biomarkers, and elevated levels of pro-inflammatory cytokines may not be related primarily to BMI but to other factors associated with obesity.

Increased release of IL-6 induces hepatic glucose generation and lipolysis, and IL-6 has been shown to link skeletal muscles contraction with exercise-induced metabolic needs (Pedersen et al., 2001). IL-6 inhibits the release of TNF- $\alpha$ explaining the latter's delayed - albeit not significant - increase 24 hours after the marathon race. Moreover, hsCRP is produced in the liver following IL-6 secretion from macrophages 
and T-cells. The half-life of hsCRP of 48 hours is constant, and therefore its level is determined by the rate of production and hence the severity of the precipitating cause. hsCRP is a marker for inflammation and for future cardiovascular events. We have shown that hsCRP is elevated after a marathon race - similar to those reported by Kim et al. (Kim, Lee, \& Kim, 2009) - independent of BMI. However, the increase in hsCRP in our study $(+1.5 \mathrm{mg} / \mathrm{ml})$ was smaller than that reported by Greene et al. (Greene, Martin, \& Crouse, 2012) $(+5.0 \mathrm{mg} / \mathrm{ml})$ who reported elevated hsCRP in overweight and obese persons 24 hours after acute exercise regardless of training. Nonetheless, hsCRP in some participants exceeded values considered as risk factor for cardiovascular disease (above $3.0 \mathrm{mg} / \mathrm{L}$ (Ridker \& Libby, 2007)) 24 hours after the marathon race. Our results showed that the effect of a marathon race on hsCRP differs largely among runners, and that the magnitude of changes in hsCRP seems to depend on marathon finishing time.

\section{Cartilage biomarkers}

Serum COMP has been associated with the incidence of knee OA (Saberi Hosnijeh et al., 2015). Immediately and 24 hours after the marathon race, more than half of our participants had values above $15 \mathrm{U} / \mathrm{L}$ previously related to a high risk of aggressive joint destruction (Andersson et al., 2013). Increases in COMP in this study were greater than those reported for shorter running exercises (Denning et al., 2014; Kersting et al., 2005; Niehoff et al., 2010; Niehoff et al., 2011) and comparable to observed changes after marathon races (Kim et al., 2009; Neidhart et al., 2000). In contrast to a previous study (Neidhart et al., 2000), COMP concentrations did not return to baseline within 24 hours after the marathon in all runners. This discrepancy may be explained by difference in study cohorts where we included runners with a larger 
variability in BMI and in running performance than previous studies. Compared to the other biomarkers assessed in this study, COMP showed the largest variability at any time point and in changes over time. This result suggests that several factors influence serum COMP.

\section{Marathon finishing time, pro-inflammatory and cartilage biomarkers}

Marathon finishing time predicted changes in serum biomarkers during the 24hour recovery after the marathon. Moreover, marathon finishing time mediated the relationship between changes in hsCRP and COMP (Figure 4). These finishing timerelated changes may represent differences in post-stress tissue metabolism between participants. There are several possible explanations for these differences. For instance, a marathon race may represent a greater relative load compared to that experienced during a typical training week requiring longer recovery time as previously reported for longer running races (Kim et al., 2009). While including weekly mileage in our linear regression models did not affect the results, this possibility is further supported by the fact that slower runners will perform more gait cycles to cover the 42-km distance than faster runners because of the small variability in stride frequency at different running speeds (Hay, 2002) and between slow and fast runners throughout a marathon (ChanRoper, Hunter, J, D, \& M, 2012). At an assumed stride frequency of 1.42 strides/s, runners in the fast third performed fewer than 19,425 strides compared to at least 22,237 steps in the slow third. Faster runners also experience greater shock absorption (Mercer, Devita, Derrick, \& Bates, 2003) although this fact may not be directly related to the load applied at the cartilage-cartilage interface at the knee because of the greater muscle forces necessary for stabilizing the knee at greater knee flexion angles during faster running (Chan-Roper et al., 2012). In addition, it is possible that the tissue metabolism 
differs between athletes varying in fitness. However, including fitness in our linear regression model (results not reported) did not affect the results. Interestingly, Vuolteenaho et al. (Vuolteenaho, Leppanen, Kekkonen, Korpela, \& Moilanen, 2014) found no changes in COMP after a marathon race but reported that observed increases in matrix metalloproteinases 3 (MMP-3) immediately after the marathon correlated negatively with marathon finishing time. A potential role of MMP-3 in exercise-induced changes in COMP was not investigated in our study.

The increase in COMP and hsCRP levels after marathon may suggest a role of inflammatory processes in stress-induced cartilage metabolism during recovery. The inflammatory potential of marathon running as previously shown (Nickel, Emslander, et al., 2012) may influence tissue metabolism and may hence be an important factor for long-term effects of marathon running. Because COMP lacks the ability to trigger a proinflammatory response in chondrocytes (Ruthard et al., 2014), increased serum COMP in slower runners may rather result from than cause the greater release of hsCRP in these participants. We included only runners without any preclinical inflammation. It is possible that the observed exercise-induced inflammatory response may be even more pronounced in patients with preclinical inflammation.

\section{Study limitations}

The limitations of this study include the size of the study cohort and selection of participants for this study. The fastest marathon finishing time in our study was just under 3 hours. Hence, none of the runners were top athletes. The finishing time groups were defined by tertiles of overall finishing times (fast $<3: 48$ hours $<$ middle $<4: 21$ hours $<$ slow) rather than by predefined performance parameters. The relationships reported in this study may thus not be readily extrapolated to runners outside of the 
reported time ranges. Similarly, including more runners with an even larger range of BMI might influence the results of the statistical analyses. Moreover, we only included selected markers for inflammation and cartilage health, and these markers do not provide sufficient explanation of potential mechanisms. We did not quantify the number of loading cycles or the load magnitude in these runners. It is possible that including these parameters would provide additional insight into the relationship between marathon finishing time and post-marathon changes in biomarkers.

\section{Conclusions}

We showed that higher BMI alone does not lead to greater increases in proinflammatory markers or cartilage markers following a marathon race. The relationship between finish-time and post-marathon changes in hsCRP and COMP suggests that being well-trained and hence performing better at a marathon results in diminished inflammatory reaction and faster recovery of cartilage after the race. However, to date the long-term effects of marathon running in heavier persons is unknown. Moreover, the importance of load-induced changes in COMP for long-term cartilage health in healthy persons and the potential development of osteoarthritis is still poorly understood.

\section{COMPETING INTEREST STATEMENT}

We declare that we have no competing interests with the authorship or publication of this contribution. 


\section{REFERENCES}

Andersson, M. L., Svensson, B., Petersson, I. F., Hafstrom, I., Albertsson, K., Forslind, K., ... Saxne, T. (2013). Early increase in serum-COMP is associated with joint damage progression over the first five years in patients with rheumatoid arthritis. BMC Musculoskelet Disorders, 14, 229. doi: 10.1186/1471-2474-14-229

Andriacchi, T. P., \& Mündermann, A. (2006). The role of ambulatory mechanics in the initiation and progression of knee osteoarthritis. Current Opinion in Rheumatology, $18(5), 514-518$

Andriacchi, T. P., Mündermann, A., Smith, R. L., Alexander, E. J., Dyrby, C. O., \& Koo, S. (2004). A framework for the in vivo pathomechanics of osteoarthritis at the knee. Annals of Biomedical Engineering, 32(3), 447-457

Bartels, E. M., Christensen, R., Christensen, P., Henriksen, M., Bennett, A., Gudbergsen, H., . . Bliddal, H. (2014). Effect of a 16 weeks weight loss program on osteoarthritis biomarkers in obese patients with knee osteoarthritis: a prospective cohort study. Osteoarthritis and Cartilage, 22(11), 1817-1825. doi: 10.1016/j.joca.2014.07.027

Bastard, J. P., Maachi, M., Lagathu, C., Kim, M. J., Caron, M., Vidal, H., . . Feve, B. (2006). Recent advances in the relationship between obesity, inflammation, and insulin resistance. European Cytokine Network, 17(1), 4-12

Celik, O., Salci, Y., Ak, E., Kalaci, A., \& Korkusuz, F. (2013). Serum cartilage oligomeric matrix protein accumulation decreases significantly after 12 weeks of running but not swimming and cycling training - a randomised controlled trial. The Knee, 20(1), 19-25. doi: 10.1016/j.knee.2012.06.001

Chan-Roper, M., Hunter, I., J, W. M., D, L. E., \& M, K. S. (2012). Kinematic changes during a marathon for fast and slow runners. Journal of Sports Science \& Medicine, 11(1), 77-82 
Denning, W. M., Woodland, S., Winward, J. G., Leavitt, M. G., Parcell, A. C., Hopkins, J. T., . . Seeley, M. K. (2014). The influence of experimental anterior knee pain during running on electromyography and articular cartilage metabolism. Osteoarthritis and Cartilage, 22(8), 1111-1119. doi: 10.1016/j.joca.2014.05.006

Despres, J. P. (2012). Body fat distribution and risk of cardiovascular disease: an update. Circulation, 126(10), 1301-1313. doi: 10.1161/CIRCULATIONAHA.111.067264

Erhart-Hledik, J. C., Favre, J., Asay, J. L., Smith, R. L., Giori, N. J., Mündermann, A., \& Andriacchi, T. P. (2012). A relationship between mechanically-induced changes in serum cartilage oligomeric matrix protein (COMP) and changes in cartilage thickness after 5 years. Osteoarthritis and Cartilage, 20(11), 1309-1315. doi: 10.1016/j.joca.2012.07.018

Greene, N. P., Martin, S. E., \& Crouse, S. F. (2012). Acute exercise and training alter blood lipid and lipoprotein profiles differently in overweight and obese men and women. Obesity (Silver Spring), 20(8), 1618-1627. doi: 10.1038/oby.2012.65

Hanssen, H., Nickel, T., Drexel, V., Hertel, G., Emslander, I., Sisic, Z., . . . Halle, M. (2011). Exercise-induced alterations of retinal vessel diameters and cardiovascular risk reduction in obesity. Atherosclerosis, 216(2), 433-439. doi:

10.1016/j.atherosclerosis.2011.02.009

Hay, J. G. (2002). Cycle Rate, Length, and Speed of Progression in Human Locomotion. Journal of Applied Biomechanics, 18, 247-270

Hsieh, C. J., Wang, P. W., \& Chen, T. Y. (2014). The relationship between regional abdominal fat distribution and both insulin resistance and subclinical chronic inflammation in non-diabetic adults. Diabetology \& Metabolic Syndrome, 6(1), 49. doi: $10.1186 / 1758-5996-6-49$ 
Kasapis, C., \& Thompson, P. D. (2005). The effects of physical activity on serum Creactive protein and inflammatory markers: a systematic review. Journal of the American College of Cardiology, 45(10), 1563-1569. doi:

10.1016/j.jacc.2004.12.077

Kersting, U. G., Stubendorff, J. J., Schmidt, M. C., \& Bruggemann, G. P. (2005). Changes in knee cartilage volume and serum COMP concentration after running exercise. Osteoarthritis and Cartilage, 13(10), 925-934

Kim, H. J., Lee, Y. H., \& Kim, C. K. (2009). Changes in serum cartilage oligomeric matrix protein (COMP), plasma $\mathrm{CPK}$ and plasma hs-CRP in relation to running distance in a marathon $(42.195 \mathrm{~km})$ and an ultra-marathon $(200 \mathrm{~km})$ race. European Journal of Applied Physiology, 105(5), 765-770. doi: 10.1007/s00421-008-0961-x

Mercer, J. A., Devita, P., Derrick, T. R., \& Bates, B. T. (2003). Individual effects of stride length and frequency on shock attenuation during running. Medicine and Science in Sports and Exercise, 35(2), 307-313. doi:

10.1249/01.MSS.0000048837.81430.E7

Messier, S. P., Pater, M., Beavers, D. P., Legault, C., Loeser, R. F., Hunter, D. J., \& DeVita, P. (2014). Influences of alignment and obesity on knee joint loading in osteoarthritic gait. Osteoarthritis and Cartilage, 22(7), 912-917. doi: 10.1016/j.joca.2014.05.013

Mündermann, A., Dyrby, C. O., Andriacchi, T. P., \& King, K. B. (2005). Serum concentration of cartilage oligomeric matrix protein (COMP) is sensitive to physiological cyclic loading in healthy adults. Osteoarthritis and Cartilage, 13(1), $34-38$ 
Mündermann, A., King, K. B., Smith, R. L., \& Andriacchi, T. P. (2009). Change in serum COMP concentration due to ambulatory load is not related to knee OA status. Journal of Orthopaedic Research, 27(11), 1408-1413. doi: 10.1002/jor.20908

Neidhart, M., Hauser, N., Paulsson, M., DiCesare, P. E., Michel, B. A., \& Häuselmann, H. J. (1997). Small fragments of cartilage oligomeric matrix protein in synovial fluid and serum as markers for cartilage degradation. British Journal of Rheumatology, $36(11), 1151-1160$

Neidhart, M., Müller-Ladner, U., Frey, W., Bosserhoff, A. K., Colombani, P. C., FreyRindova, P., . . Gay, S. (2000). Increased serum levels of non-collagenous matrix proteins (cartilage oligomeric matrix protein and melanoma inhibitory activity) in marathon runners. Osteoarthritis and Cartilage, 8(3), 222-229

Nickel, T., Emslander, I., Sisic, Z., David, R., Schmaderer, C., Marx, N., . . Hanssen, H. (2012). Modulation of dendritic cells and toll-like receptors by marathon running. European Journal of Applied Physiology, 112(5), 1699-1708. doi: 10.1007/s00421$011-2140-8$

Nickel, T., Hanssen, H., Emslander, I., Drexel, V., Hertel, G., Schmidt-Trucksass, A., ... Weis, M. (2011). Immunomodulatory effects of aerobic training in obesity. Mediators of Inflammation, 2011, 308965. doi: 10.1155/2011/308965

Nickel, T., Vogeser, M., Emslander, I., David, R., Heilmeier, B., Op den Winkel, M., .. . Halle, M. (2012). Extreme exercise enhances chromogranin A levels correlating with stress levels but not with cardiac burden. Atherosclerosis, 220(1), 219-222. doi: 10.1016/j.atherosclerosis.2011.09.036 
Niehoff, A., Kersting, U. G., Helling, S., Dargel, J., Maurer, J., Thevis, M., \& Bruggemann, G. P. (2010). Different mechanical loading protocols influence serum cartilage oligomeric matrix protein levels in young healthy humans. European Journal of Applied Physiology, 110(3), 651-657. doi: 10.1007/s00421-010-1529-0

Niehoff, A., Muller, M., Bruggemann, L., Savage, T., Zaucke, F., Eckstein, F., . . . Bruggemann, G. P. (2011). Deformational behaviour of knee cartilage and changes in serum cartilage oligomeric matrix protein (COMP) after running and drop landing. Osteoarthritis and Cartilage, 19(8), 1003-1010. doi: 10.1016/j.joca.2011.04.012

Pedersen, B. K., Steensberg, A., Fischer, C., Keller, C., Ostrowski, K., \& Schjerling, P. (2001). Exercise and cytokines with particular focus on muscle-derived IL-6.

Exercise Immunology Review, 7, 18-31

Petelin, A., Bizjak, M., Cernelic-Bizjak, M., Jurdana, M., Jakus, T., \& Jenko-Praznikar, Z. (2014). Low-grade inflammation in overweight and obese adults is affected by weight loss program. Journal of Endocrinological Investigation, 37(8), 745-755. doi: $10.1007 / \mathrm{s} 40618-014-0102-9$

Pruksakorn, D., Tirankgura, P., Luevitoonvechkij, S., Chamnongkich, S., Sugandhavesa, N., Leerapun, T., \& Pothacharoen, P. (2013). Changes in the serum cartilage biomarker levels of healthy adults in response to an uphill walk. Singapore Medical Journal, 54(12), 702-708

Ridker, P. M., \& Libby, P. (2007). Risk Factors for Atherothrombotic Disease. In P. Libby, R. O. Bonow, D. L. Mann \& D. P. Zipes (Eds.), Braunwald's Heart Disease: A Textbook of Cardiovascular Medicine (8th edition ed.). Philadelphia, Pa: Saunders Elsevier. 
Runhaar, J., Koes, B. W., Clockaerts, S., \& Bierma-Zeinstra, S. M. (2011). A systematic review on changed biomechanics of lower extremities in obese individuals: a possible role in development of osteoarthritis. Obesity Reviews, 12(12), 1071-1082. doi: 10.1111/j.1467-789X.2011.00916.x

Ruthard, J., Kamper, M., Renno, J. H., Kuhn, G., Hillebrand, U., Hollriegl, S., . . Klatt, A. R. (2014). COMP does not directly modify the expression of genes involved in cartilage homeostasis in contrast to several other cartilage matrix proteins.

Connective Tissue Research, 55(5-6), 348-356. doi: 10.3109/03008207.2014.951440

Saberi Hosnijeh, F., Runhaar, J., van Meurs, J. B., \& Bierma-Zeinstra, S. M. (2015). Biomarkers for osteoarthritis: Can they be used for risk assessment? A systematic review. Maturitas. doi: 10.1016/j.maturitas.2015.04.004

Schiffer, T., Montiel, G., Hildebrandt, U., Predel, H. G., \& Knackstedt, C. ( 2010). Der Marathonlauf als gesundheitliches Risiko? Klinikarzt, 39, 288-291

Schjerve, I. E., Tyldum, G. A., Tjonna, A. E., Stolen, T., Loennechen, J. P., Hansen, H. E., .. . Wisloff, U. (2008). Both aerobic endurance and strength training programmes improve cardiovascular health in obese adults. Clinical Science, 115(9), 283-293. doi: $10.1042 / \mathrm{CS} 20070332$

Schmitt, H., Rohs, C., Schneider, S., \& Clarius, M. (2006). [Is competitive running associated with osteoarthritis of the hip or the knee?]. Orthopade, 35(10), 1087-1092. doi: 10.1007/s00132-006-0998-7

Vadeboncoeur, T. F., Silvers, S. M., Taylor, W. C., Shapiro, S. A., Roth, J. A., Diehl, N., . . Mohseni, M. M. (2012). Impact of a high body mass index on lower extremity injury in marathon/half-marathon participants. Journal of Physical Activity \& Health, 9(1), 96-103 
Vincent, H. K., Heywood, K., Connelly, J., \& Hurley, R. W. (2012). Obesity and weight loss in the treatment and prevention of osteoarthritis. $P M \& R, 4(5 \mathrm{Suppl})$, S59-67. doi: 10.1016/j.pmrj.2012.01.005

Vuolteenaho, K., Leppanen, T., Kekkonen, R., Korpela, R., \& Moilanen, E. (2014).

Running a marathon induces changes in adipokine levels and in markers of cartilage degradation--novel role for resistin. PLoS One, 9(10), e110481. doi:

10.1371/journal.pone.0110481

Williams, P. T. (2012). Attenuating effect of vigorous physical activity on the risk for inherited obesity: a study of 47,691 runners. PLoS One, 7(2), e31436. doi: 10.1371/journal.pone.0031436 


\section{Tables}

Table 1. Demographics of the participants of this study at baseline and after a 10week running training.

\begin{tabular}{|c|c|c|c|}
\hline Parameter & Baseline & $\begin{array}{l}\text { After 10-week } \\
\text { running training }\end{array}$ & $P$-value \\
\hline Age (years) & $\begin{array}{c}40.0 \\
{[38.2 ; 41.8]}\end{array}$ & & \\
\hline Height $(\mathrm{cm})$ & $\begin{array}{c}180.8 \\
{[178.8 ; 182.8]}\end{array}$ & & \\
\hline Body mass $(\mathrm{kg})$ & $\begin{array}{c}83.6 \\
{[79.4 ; 87.8]}\end{array}$ & $\begin{array}{c}82.3 \\
{[78.2 ; 86.5]}\end{array}$ & $<.001$ \\
\hline BMI $\left(\mathrm{kg} / \mathrm{m}^{2}\right)$ & $\begin{array}{c}25.5 \\
{[24.5 ; 26.5]}\end{array}$ & $\begin{array}{c}25.0 \\
{[24.0 ; 26.1]}\end{array}$ & $<.001$ \\
\hline Body fat (\%) & $\begin{array}{c}18.2 \\
{[16.2 ; 20.3]}\end{array}$ & $\begin{array}{c}16.2 \\
{[14.4 ; 18.0]}\end{array}$ & $<.001$ \\
\hline $\begin{array}{l}\text { Waist circumference } \\
(\mathrm{cm})\end{array}$ & $\begin{array}{c}91.0 \\
{[87.5 ; 94.5]}\end{array}$ & $\begin{array}{c}89.1 \\
{[85.8 ; 92.4]}\end{array}$ & .001 \\
\hline $\begin{array}{l}\text { Training distance } \\
\text { (km/week })\end{array}$ & & $\begin{array}{c}43.5 \\
{[38.8 ; 48.3]}\end{array}$ & \\
\hline $\begin{array}{l}\text { Marathon finishing time } \\
\text { (min) }\end{array}$ & & $\begin{array}{c}247 \\
{[235 ; 258]}\end{array}$ & \\
\hline $\begin{array}{l}\text { Tertile groups marathon } \\
\text { finishing time (min) } \\
\text { fast } \\
\text { middle } \\
\text { slow } \\
\end{array}$ & & $\begin{array}{c}\quad<228 \\
228 \text { to } 261 \\
\quad>261 \\
\end{array}$ & \\
\hline $\begin{array}{l}\text { Mean }[95 \% \text { confidence } \\
\text { parameters are given for } \\
\text { BMI - body mass index }\end{array}$ & $\begin{array}{l}\text { are given for } \\
\text { nning and enc } \\
\text { s are providec }\end{array}$ & $\begin{array}{l}\text { eters. BMI and } \\
\text { week running tr } \\
\text { ent t-test for de }\end{array}$ & $\begin{array}{l}\text { lance } \\
\text { rogram. }\end{array}$ \\
\hline
\end{tabular}


Table 2. Statistical results of the generalized linear models.

\begin{tabular}{lccc}
\hline Factor & F-value & P-value & Observed power \\
\hline IL-6 & $\mathbf{1 9 . 5 8 3}$ & $<\mathbf{0 . 0 0 1}$ & $\mathbf{1 . 0 0 0}$ \\
time & 0.035 & 0.991 & 0.056 \\
time $\times$ BMI & 0.485 & 0.693 & 0.146 \\
time $\times$ finish time & & & 0.091 \\
\hline TNF- $\alpha$ & 0.223 & 0.880 & 0.094 \\
time & 0.238 & 0.869 & 0.066 \\
time $\times$ BMI & 0.093 & 0.964 & \\
time $\times$ finish time & & & $\mathbf{0 . 9 0 8}$ \\
\hline$h C R P$ & $\mathbf{5 . 0 2 5}$ & $\mathbf{0 . 0 0 3}$ & 0.129 \\
time & 0.410 & 0.746 & $\mathbf{0 . 9 7 1}$ \\
time $\times$ BMI & $\mathbf{6 . 6 9 9}$ & $<\mathbf{0 . 0 0 1}$ & \\
time $\times$ finish time & & & $\mathbf{0 . 9 6 2}$ \\
\hline COMP & $\mathbf{6 . 2 8 7}$ & $\mathbf{0 . 0 0 1}$ & 0.103 \\
time & 0.280 & 0.840 & $\mathbf{0 . 9 9 6}$ \\
time $\times$ BMI & $\mathbf{9 . 2 7 7}$ & $<\mathbf{0 . 0 0 1}$ & \\
time $\times$ finish time & a & &
\end{tabular}

Generalized linear models were used for detecting changes in serum biomarker concentrations over time with covariates BMI and marathon finish time. Significant differences of the generalized linear model with factor time and covariates BMI and marathon finish time are shown as bold numbers $(P<0.001)$. IL-6 - interleukin 6; TNF$\alpha$ - tumor necrosis factor $\alpha$; hsCRP - high sensitivity C-reactive protein; COMP cartilage oligomeric matrix protein; BMI - body mass index. 
Table 3. Statistical results of the linear regression models.

\begin{tabular}{|c|c|c|c|c|c|}
\hline Model & Coefficient & Standard error & t-Statistic & Probability & $R^{2}$ \\
\hline \multicolumn{6}{|l|}{$h s C R P$} \\
\hline Constant & -1.592 & 0.744 & -2.139 & 0.039 & \\
\hline Finishing time & 0.013 & 0.003 & 4.234 & $<0.001$ & 0.320 \\
\hline \multicolumn{6}{|l|}{ COMP } \\
\hline Constant & -13.330 & 3.349 & -3.980 & $<0.001$ & \\
\hline Finishing time & 0.055 & 0.013 & 4.134 & $<0.001$ & 0.284 \\
\hline \multicolumn{6}{|c|}{$\begin{array}{l}\text { Linear regression models were used for detecting the effects of BMI and marathon } \\
\text { finishing times on changes in biomarkers from immediately after to } 24 \text { hours after the } \\
\text { marathon race. hsCRP - high-sensitivity C-reactive protein; COMP - cartilage } \\
\text { oligomeric matrix protein. }\end{array}$} \\
\hline
\end{tabular}




\section{FIGURE LEGENDS}

\section{Figure 1. Illustration of the study protocol.}

The study protocol involved blood samples before and after a 10-week endurance training and a marathon race.

\section{Figure 2. Changes in IL-6 and TNF- $\alpha$ serum concentration over time.}

IL-6 and TNF- $\alpha$ serum concentrations at baseline, after a 10 -week running training program (before marathon race) and immediately and 24 hours after a marathon race. Small figures show individual changes in concentrations from before to after the marathon race or from immediately to 24 hours after a marathon race, respectively. Horizontal bars indicate significant differences between time points (posthoc tests: repeated measured t-tests, $P<0.005)$.

\section{Figure 3. Changes in hsCRP and COMP serum concentration over time.}

hsCRP and COMP serum concentrations at baseline, after a 10 -week running training program (before marathon race) and immediately and 24 hours after a marathon race. Small figures show individual changes in concentrations from before to after the marathon race or from immediately to 24 hours after a marathon race, respectively. Horizontal bars indicate significant differences between time points (posthoc tests: repeated measured t-tests, $P<0.005)$. 
Figure 4. Association of follow-up changes in hSCRP and COMP and marathon performance.

Relationship between mean (standard error) changes in hsCRP and COMP from immediately to 24 hours after a marathon race depending on marathon finishing time tertile groups. 


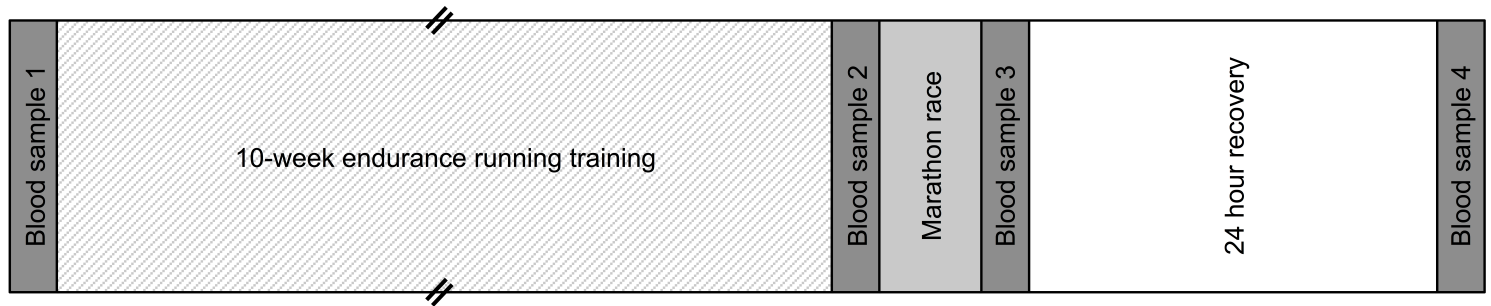

Figure 1 

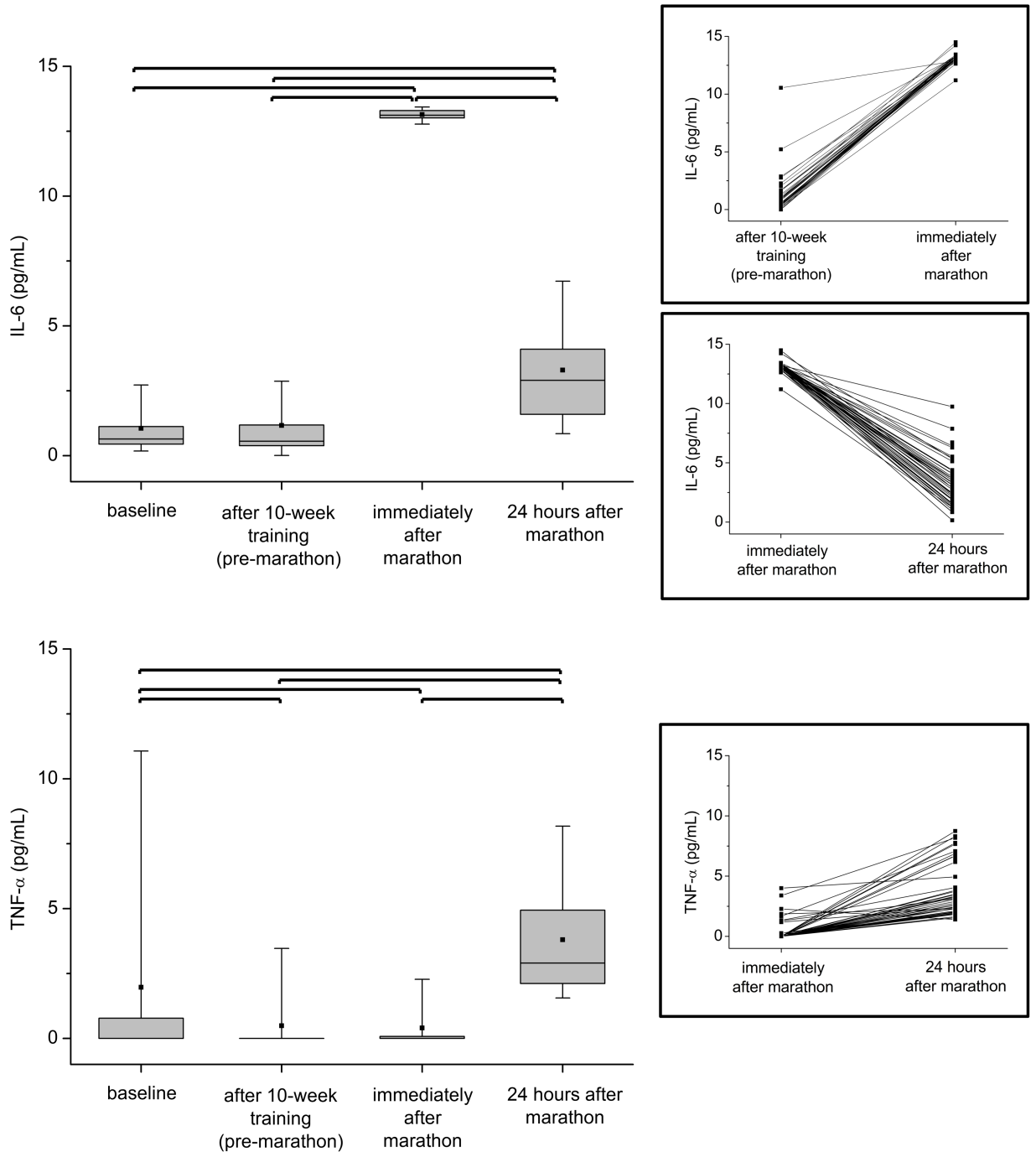

Figure 2 

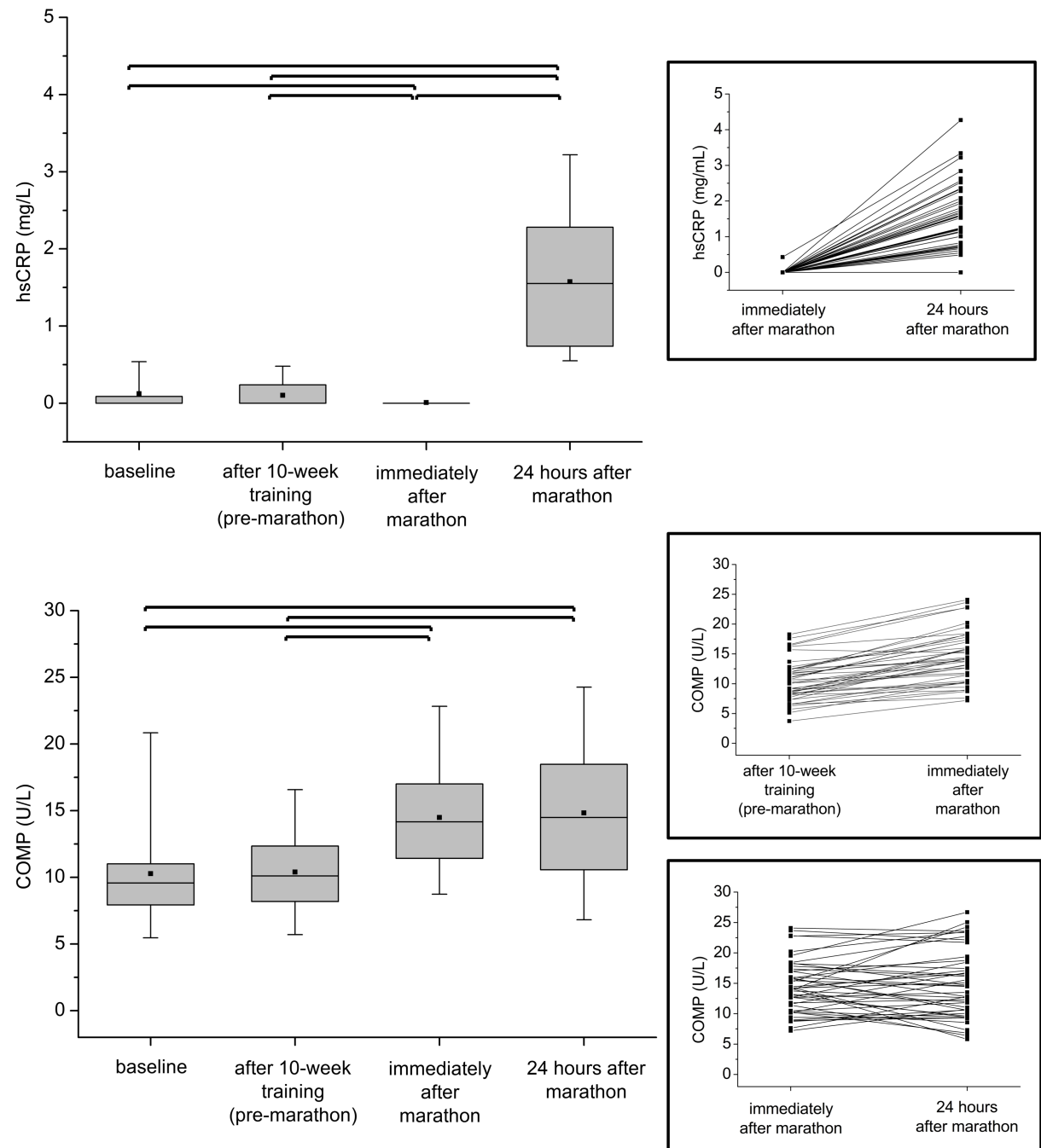

Figure 3 


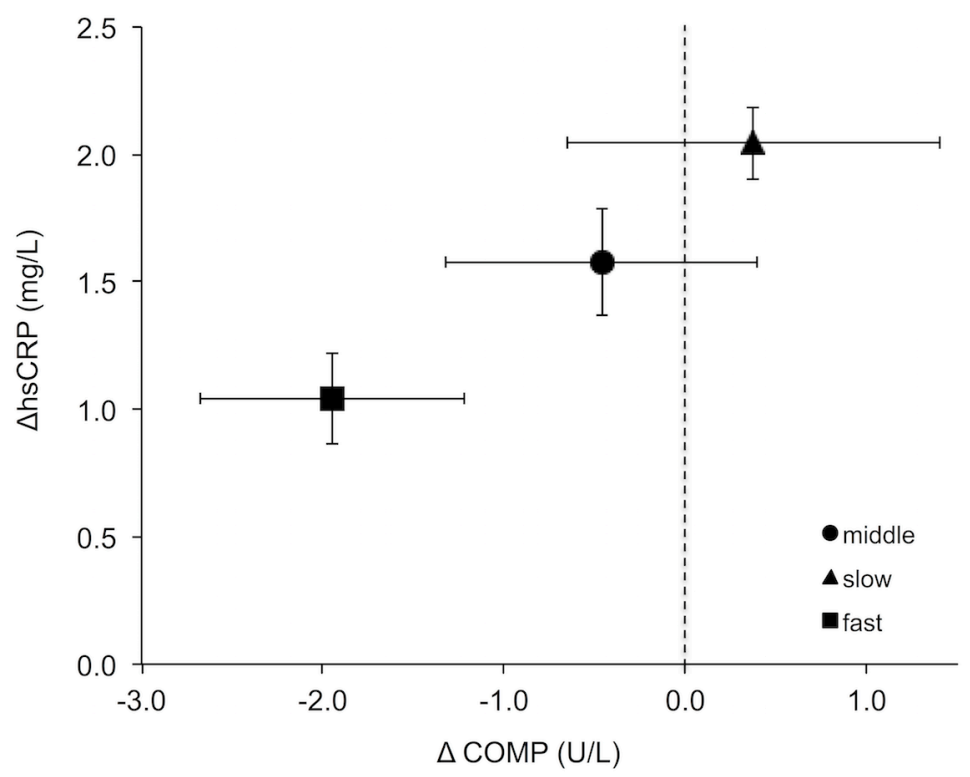

Figure 4 